\title{
A Feasibility Research on the Mechanism of Cold Chain Business in Deppon Logistics
}

\author{
Yanni $\mathrm{Li}^{1}$, Yunyun $\mathrm{Xu}^{1}$, Baichao Gong ${ }^{1}$, Haopeng $\mathrm{Sun}^{3}$ and Fuguang Zhao ${ }^{2, *}$ \\ ${ }^{1}$ School of Foreign Languages, Changchun Institute of Technology, No.395 \\ Kuanping Road, Changchun, Jilin, 130012, China \\ ${ }^{2}$ School of Life Science, Jilin Agricultural University, No. 2888 Xincheng Street, \\ Jilin 130118, China \\ ${ }^{3}$ School of Software Engineering, Changchun Institute of Technology, No.395 \\ Kuanping Road, Changchun, Jilin, 130012, China
}

\begin{abstract}
Cold chain distribution is always well-known as the "Mount Everest" in international logistics industry, while the rapid development in recent years of domestic meat, frozen food, cold drinks industry and dairy industry brought a leapfrog growth of cold chain logistics, which respectively stimulated the need for logistics outsourcing service from Third Party Logistics. Those companies demanding for exploiting cold chain business on one hand requires a complete set of refrigerated logistics chains, on the other hand also requires enterprises to establish a good and professional transport system with refrigerated operation equipment, which are precisely the weakness of manufacturing enterprises. Thus, outsourcing of cold chain logistics to a third party is the best choice for companies to focus on its core business. By analyzing the bulletins of International Cold Chain Logistics Summits, this paper shows the problems of cold chain industry in China and points out the potentials for its future development. It further analyzes the feasibility of launching cold chain business of Deppon Logistics. The purpose is to offer some suggestions to work out the barriers and set up a modern operation system under the big data age in Deppon.
\end{abstract}

Keywords: Cold chain logistics, Deppon Logistics, operation system, big data

\section{Introduction}

With China's rapid economic development and rising level of household consumption, people's needs for agricultural products, especially vegetables, fruit, meat, aquatic products increased rapidly, accordingly, requirements for its intrinsic quality and safety are increasing. Time for developing the cold chain is also ripen, which means a sore need of improving the development of cold chain logistics and cold chain market and striving to develop the 3rd party logistics[3]. As a leading enterprise of domestic highway logistics business, whatever in the construction of the information system and standardization system construction, and logistics network construction and professional service level, the Deppon logistics has accumulated quite a mighty voice in this industry.

As a graduating college student ambitious to plunge into the logistics, if you can grasp the essence of this line before your entry, it would be a quite proactive mind.

As many domestic 3rd party logistics are hesitating to advance or keep on halting.

While recently the news that the SF-Express signed a strategic cooperation agreement with Lenovo Joyvio to march towards the cold chain logistics, which is a creative starting point for domestic big 3rd party logistics companies.

* Corresponding Author 
The most important thing is that this start will definitely lead to a demonstration effect of establishing complete information platform. In this market competition, Deppon should not do nothing, or rather, Deppon should set a longsighted goal to grab this opportunity.

On the one hand, the release of the "Cold Chain Spider Plan" quickly set off the whole industry, which aims to build information platform and integrate the resource channels for enterprises. In the era of big data, the RFID, the microblog, the QR code, bar code, the GPS and many other new technologies emerge in endlessly and are applied into the logistics. But a complete independent cold chain logistics system has not formed. This plan brought hope for establishing a professional big cold chain platform. On the other hand, according to our investigation, the Deppon grown rapidly in recent years, and its logistics net has covered most part of China, and there will increase on average 100 outlets every month. The increasingly sophisticated logistics network of Deppon lays a solid foundation for opening up the cold chain business.

\section{Current Situation of Cold Chain Logistics in China}

Cold Chain Logistics is a process of low temperature logistics taking freezing technology as the basis and cooling technology as the means. With the economic development and the improvement of living standard, demand for cold chain logistics in China is now growing; the process of cold chain logistics is now being standardized; the enterprises in this industry is now developing; and development of IT in this industry is now in the primary stage. But there are still some problems with this industry, such as the problems with the main players of this industry, the imperfect infrastructure, the lagged behind development of food cold chain logistics and the lack of integrated plan for the up and down stream resources [9].

\subsection{The Competitive Landscape of Cold Chain Logistics}

Therefrigerated logistics of our country is still at an early stage, at which is featured with the small market scale, strong regional features and lack of influential, nationwide 3rd party logistics leaders. The current domestic logistics companies mainly beyond to the following forms:

3rd party logistics companies, this type includes companies entering the cold chain logistics from traditional logistics enterprises, such as SF-Express, Shandong Rokin and so on; also, includes companies focusing on cold chain business, like KX Logistics and Yamato Transportation, and HAVI Group. The latter has a long-term cooperation with McDonald's and has a sophisticated logistics system.

Then where should be the start industry in the first business, meat product, quickfrozen food, dairy products, aquatic product or cold drinks? The author thinks that the rising of fresh product e-commerce as SF-best, Alibaba etc., provided the 3rd logistics companies a heaven-sent opportunity. On the one hand, the fresh ecommerce leaders put large investment in the cold chain and logistics, and aim to build a whole chain from the original place to the users; on the other hand, they are committed to building a integrated solution, establishing a set of industry standards, which covers front procurement, quality inspection, storage and preservation, cold chain transport and distribution. The author thinks that in the era of big data the cooperation with those e-commerce enterprises will be a great tendency which is bound to rise a revolution of this industry.

\subsection{The Latest Cold Chain Equipment and Technologies and the Supportive Policies}

Cold chain logistics generally follow the principle of 3T, which the ultimate quality of product depends on the storage. The cold chain logistics system demands 
highly for the collection and delivery of information, time-control, and temperaturecontrol. Then how to integrate all of the links and efficiently monitor the time and temperature of the whole process of logistics. This is where the technologies and equipment should work in the construction of logistics system.

To guarantee the operational standardization of this logistics transport, recording and tracking the temperature, controlling the temperature equipment and inspecting the product acceptance, the RFID technology was applied to the cold chain logistics, which is a non-contact automatic identification technology. Through radio waves, it can automatically identify the target and access to the relevant data without any manual intervention. And it can work in various harsh environment. The most important thing is that in can work beyond your sight and the identification distance is farther than optical systems. And its radio frequency identification card can read and write and is capable of carrying a large amount of data, which is very convenient for information collection in the era of big data [1].

Due to involving the food safety, there must be many rules to follow in the construction of cold chain logistics. Especially the exposure of OSI events hit heavily the system of food safety. The upcoming policies will surely tend more to the supervision of food safety [4]. And as a non-core business, if the manufacturer takes proprietary cold chain logistics, the high investment of infrastructure facilities and equipment can only serve their own business, that's really not a wise choice. Thus, the road to 3rd party logistics seems to be brighter.

\subsection{The Current Market Cases of the 3rd Party Logistics Enterprises Entering the Cold Chain Logistics Industry}

As recently the news that SF-Express signed a strategic cooperation agreement with Lenovo Joyvio to march towards the cold chain logistics, which is a creative starting point for domestic big 3rd party logistics companies. The logistics distribution of SF-Best will be overall undertaken by SF-Express, which connected the supply chain of high-end and high quality of SF-Express. This express giant should stretch out its business into the cold chain, and furthermore opting the TECENT as its information in-and-out tool, whether this step is a long-term view or speculating behavior, it remains to be seen.

In addition, in the general e-commerce field, depended on respective contracted logistics platforms, just like a catfish, fresh business agitated the whole cold chain industry bustlingly. Except Alibaba, JD the two battlefields, many other different sub-battlefield are extraordinarily, wonderful. Apart from the most basic B2B model, F2C, B2C, O2O and many other innovative model flooded into people's mind.

Though the cold chain in 2014 is still that all we hear is thunder, but no rain falls, the shining point still exists. Firstly the capital from home and abroad flooded into this industry, Amazon stake 20 million dollars into the local fresh electronic platform of Yummy 77 in Shanghai; then the Womai of COFCO obtained 100 million dollars financial support from IDG and SAIF Partners. Consequently, the strong capital input ensured the market vigor of cold chain industry.

The $\mathrm{O} 2 \mathrm{O}$ model nowadays has been rushed into many e-business companies. In 2014, JD teamed up with the Vanguard convenience store and ZhangZhidao; YHD combined with Walmart. Meanwhile, many other powerful cross-border electric business platforms are gradually rising [11].

However, there is no overlord in the field of cold chain industry. Although companies as Alibaba, JD and other e-commerce giants and business giants as Chuanzhi Liu, Shiyi Pan and other top-notch respectively involved in sharing this market, the one who truly gained much is rare. To all those setting foot in cold chain industry, it is a must to know that luck comes after hardship. While there are still 
other reasons which can cause the risks, like lack of management for renewing software and hardware led to the threats, so a joint management system from all the parties should be set up to ensure the safety [5].

\section{The Feasibility of Exploiting Cold Chain Business in Deppon}

As the bellwether of express, SF flung itself into the cold chain industry; as the head of high-end logistics, does Deppon have reason to stand still? This is not a matter of blind-mind, this is a matter of industry trend.

\subsection{The Strengths and Weakness of Deppon Logistics}

Deppon logistics, a leading integrated service-oriented logistics provider with the national $5 \mathrm{~A}$ qualification, is dedicated to the domestic road and air freight services. Deppon has more than 5,300 outlets in 32 provinces, municipalities and autonomous regions (by 2014 October). Deppon boasts its widest coverage of customized transport service network in 550-plus cities and regions across China with more than 8,900 freight vehicles, its whole warehousing area is over $1,050,000 \mathrm{~m}^{2}$, offering a full range of products and services like precision GPS-enabled road express service, precision intercity freight service, precision road freight service, and precision air freight service etc. Ever since its establishment in 1996, Deppon has maintained the annual growth ratio of over $60 \%$ for consecutive years.

The reason why the author chose Deppon logistics other than other enterprises for exploiting cold chain business can obviously be picked out from the above. Actually, the competition among logistics companies is the competition of capital, technologies and talents. As long as you have even a little conception for the standardization logistics, a kind of kindred spirit will strike your heart. And a word "precision" cross through your impression, Deppon is easily described as a group of maniac who inject stimulant in the whole day. It is that kind of corporate culture that accomplished its rapid development. On the one hand, the perception for precision in Deppon conforms to the requirements of cold chain; on the other hand, unlike other stereotyped logistics enterprises, Deppon is on a fast developing lane, and many areas will be the first, and its capital accumulation in these years greatly supported its expansion into larger market space. As mentioned before, as the "Mount Everest" in the international logistics industry, the author was in an inspired mood to draw a blueprint for Deppon developing cold chain business. In this part, the strengths and weakness of Deppon will be analyzed from three aspects: talents, technologies and enterprise management.

"Low, small, scattered and chaotic" was once synonymous with logistics, and Deppon is of no exception. From the primary cooperation with colleges, to have training program and to the present campus recruitment, the talents strategy of Deppon experienced a milestone development. The reason why company would adopt such talent policy as those intelligence-intensive industry is that, for one thing, the talents basis of Deppon is fragile and lack of substantial innovative motion; for the other thing, the market demand makes company promote service quality and management level, for that needs a large group of outstanding people. In Deppon, $99 \%$ of management team-leaders are generated from internal training. However, seeing from another perspective, we can conclude that the loophole of talents in Deppon is still severe.

The second, as referred above, in the set of Big Data Era, the application of hightech to the logistics becomes necessary. Relatively speaking, the high demands for transporting and warehousing of cold chain rightly meet this trend. The wide use of bar-coding technology, smart label, GPS, RFID, EDI and many other high-tech create a smart logistics network. Since 2010, RFID technology has been generalized 
in Deppon. In the future, every outlets of Deppon could share the latest industry and company information. As for the EDI and GPS, their application has become mature. However, as the expansion of services network of Deppon, especially at those root area, the management must be clear about fiscal expenditure.

Last but not least, it is a truth universally acknowledged that one general is harder to come by than a thousand soldiers. As mentioned above, the precision concept has deeply rooted in the career ethics of Deppon people. Since 2006, the job rotation system has been introduced into Deppon, unlike those ordinary shift-work, the job rotation in Deppon got its own characteristics, which has evolved a mature employee training system. And by means of this effective framework, the company has brought up many team leaders to meet the rapid growth of business. In consequence, rocket-promotion in Deppon is never rare.

\subsection{The Comparison among Domestic Logistics Enterprises}

Before we rashly engage in idle theorizing to such a splendid plan. Let's take a look at a set of data in Figure 1.

This figure naturally leads to a conclusion that the growth trend of Deppon is inspiring, which there are nearly 1000 new outlets generated every year, and the company revenue increases by $60 \%$ than the last year. Deppon is always very proud of its specialization philosophy and this kind of specialization has boosted the company becoming one of the leaders of LTL(less-than-truckload) logistics. However, in November 2013, Deppon announced express business online. From personal standing, this decision adjusted the demands of the industry and trend, and effectively reflected the growth of average $60 \%$ every year. Thus, marching into the cold chain business one day is a must.

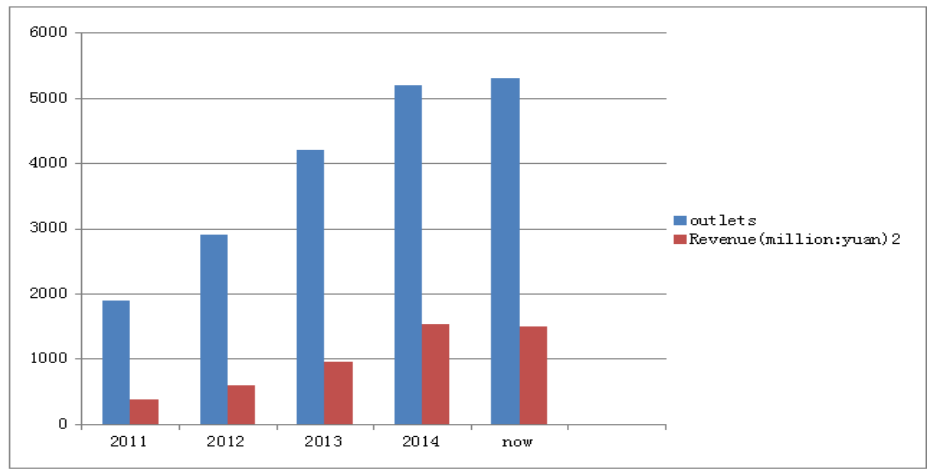

Figure 1. The Business Growth of Deppon

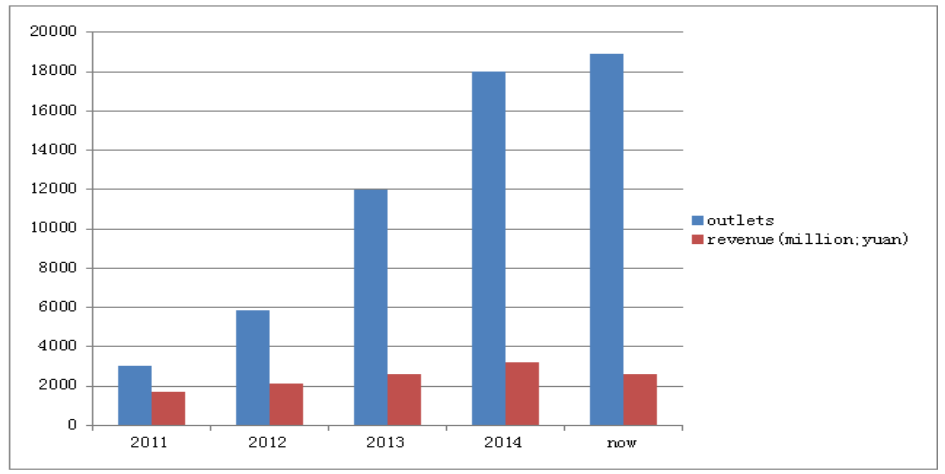

Figure 2. The Business Growth of SF 
Entering the second decades of 21 st century, to develop the cold chain logistics is imminent and the government policies are intensively issued, many enterprises also stake market. On 25th September of 2014, SF-Express announced that it will integrate its current logistics, e-commerce, outlets and some other resources to found SF-Cold Chain. Respectively, its refrigeration house has been building in some area.

Different from SF-Express, based on express delivery, SF has more well-knit operational reserve, shown in Figure 2. Though Deppon opened its express delivery in 2013, there is one point that SF must admire that the talents reserve of Deppon is very far-sighted, because the market position of two companies is different: highend logistics and express delivery. From this graph, SF opened its cold chain business in 2013, it's a time that its all-pervasive resources are tending to be mature. The cold chain is a high technological industry, thus the demands for talents are very critical. At this point, Deppon is very proud of these years' attempt.

Through this comparison, firstly, it's worthwhile for Deppon to open its express business, and with its logistics net becoming thorough, the matter of exploiting cold chain business should be put on agenda; secondly, Deppon at present is on a fast growing lane, but traditional logistics market tends to be saturated, the management must try to find another industry to keep this growing impetus, the cold chain logistics is just that field of gold.

\section{Discussion}

Now that the cold chain logistics is recognized as a sunrise industry, and the momentum of growth of Deppon is overwhelming, Whether Deppon is apt to develop cold chain, its internal business manipulation may help remove people's suspicion (Figure 3). Here is a business model in allusion to B2B model of $3^{\text {rd }}$ party logistics:

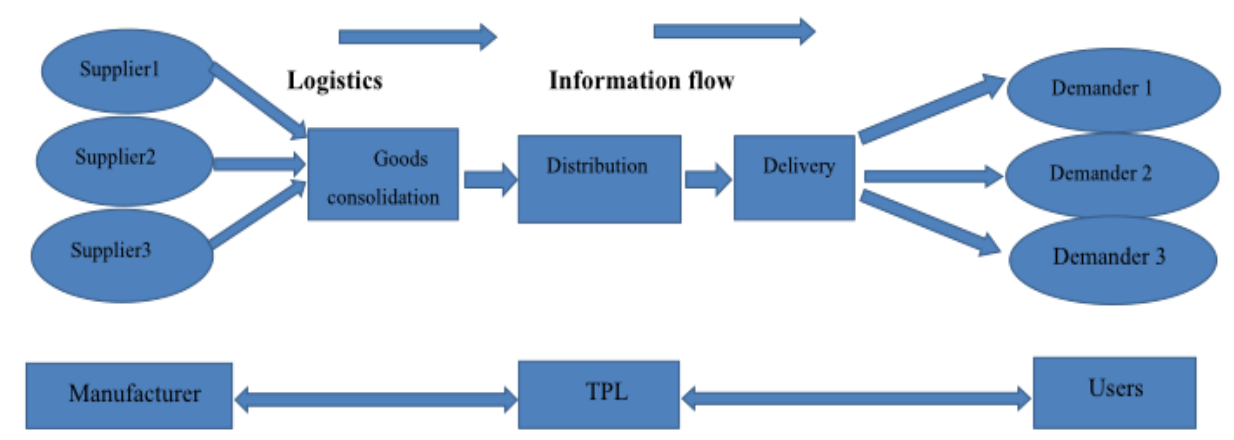

Figure 3. The Business Model of Logistics Enterprises

This figure also describes the whole process of distribution, you can see it as a B2B mode or a B2C mode. It is in the every link of this process that those IT technologies are implied and create a high-efficiency work environment. With the development of intensification and integration of the distribution of TPL, the logistics often need to link all aspects of distribution, and its core is the process of goods consolidation, distribution and delivery. To optimize the distribution system should mainly focus on the optimization of scheduling the distribution and delivery tools, which includes the route optimization, integration optimization and other aspects.

\subsection{The Barriers as Deppon Logistics Exploiting the Cold Chain Business}

1. The rigorous demands for cold chain transport 
Like the old saying that it's the first step that costs troublesome. As a freshman in the cold chain business, the road ahead of Deppon is still too long, which may exists twists and turns. To take SF-Express as an example, to open up the cold chain business, the most important thing is the infrastructure construction, and SF invested over 8 billion yuan to complete the whole chain. Benefited from its root-express, SF Cold Chain could pick up its previous logistics network. And supported from its ecommerce platform, which is being explored and tending towards perfection, naturally, B2C business model became its ideal pattern. So the decision-makers of Deppon must take a promising business target that is fit to the company: B2B model, B2C or F2B, F2C, etc., and as the whole process concerns with the temperature control, it's vital for keeping food safety to construct the temperature monitoring and warning system in the transporting series.

Hereby this paper takes B2B model as an example to state the high standard of cold chain. As stipulation, the temperature must be kept around $-22^{\circ} \mathrm{C}$ as the frozen control point, and the refrigeration control point is $8^{\circ} \mathrm{C}$. Products that need cold chain logistics mainly include agriculture, medicine, cosmetics, wine and some others. But different products require different temperature standards. And respectively, the refrigerated storage, frozen storage, fresh storage and air conditioned warehouse of different temperature standard must be scientifically designed and built, which can be shown in Figure 4 (data from the provision of the current national related standards).

\begin{tabular}{|c|c|c|c|c|}
\hline NO. & $\begin{array}{l}\text { Name of Cold } \\
\text { Room }\end{array}$ & Temperature & $\begin{array}{c}\text { Relative } \\
\text { Humidity }(\%)\end{array}$ & Scope of Products \\
\hline 1 & $\begin{array}{c}\text { Chilling } \\
\text { Room }\end{array}$ & $0 \sim 4$ & $\sim \sim$ & Meat, egg and so on \\
\hline \multirow{2}{*}{2} & \multirow{2}{*}{$\begin{array}{l}\text { Freezing } \\
\text { Room }\end{array}$} & $18 \sim-23$ & \multirow{2}{*}{$\sim \sim$} & Meat, poultry, iced eggs and so on \\
\hline & & $-23 \sim-30$ & & Fish and shrimp, etc \\
\hline \multirow{8}{*}{3} & \multirow{8}{*}{$\begin{array}{l}\text { Cooling } \\
\text { products } \\
\text { Spring house }\end{array}$} & 0 & $85 \sim 90$ & Cooled meat and poultry \\
\hline & & $-2 \sim 0$ & $80 \sim 85$ & Fresh eggs \\
\hline & & $-1 \sim 1$ & $90 \sim 95$ & Iced fresh fish \\
\hline & & $0 \sim 2$ & $85 \sim 90$ & Apple, peach and others \\
\hline & & $-1 \sim 1$ & 90 95 & $\begin{array}{c}\text { Cabbage, garlic, onion, coriander, } \\
\text { carrot, celery and many other } \\
\text { vegetables }\end{array}$ \\
\hline & & $2 \sim 4$ & $85 \sim 90$ & Potato, orange and lychee, etc \\
\hline & & $7 \sim 13$ & $85 \sim 95$ & Tomato, pineapple, citrus andothers \\
\hline & & $11 \sim 16$ & $85 \sim 90$ & Banana \\
\hline \multirow[t]{2}{*}{4} & \multirow{2}{*}{$\begin{array}{l}\text { Cold products } \\
\text { Springhouse }\end{array}$} & $\begin{array}{l}-15 \sim-20 \\
\end{array}$ & $85 \sim 90$ & $\begin{array}{c}\text { Frozen meat, poultry, ice cream, and } \\
\text { some frozen vegetables }\end{array}$ \\
\hline & & $-18 \sim-25$ & $90 \sim 95$ & Frozen fish, shrimp, frozen beverage. \\
\hline 5 & Icehouse & $-4 \sim-6$ & $\sim \sim$ & Ice block made of salt water. \\
\hline
\end{tabular}

Figure 4. The Standards of Temperature and Humidity of Cold Chain Products

Furthermore, such mechanical equipment as refrigerating unit like air compressor, heat insulating material, transportation devices and so on. But technically, those equipment on earth need technicians to operate, so the introduction of referring engineers is also an important work, maybe the company could make full use of the advantages of campus recruitment. The good news is that these industries in China are still in an immature stage. And there is still a market to be developed [10]. 


\subsection{High Operation Costs and Long Cycle}

Since cold chain is the top logistics of this industry, and as mentioned above, the design and building of refrigerated storage, frozen storage, fresh storage and air conditioned warehouse of different temperature standard, the procurement of cold chain equipment, the introduction of engineers, etc, which require high investment, if not, the product safety problems, especially for the food, may take a serious disaster to the society and company. The most painful example may be the recent OSI event.

One point that may be a barrier is the limit of land resource, which is built for the logistics center, including the refrigeration storage, thus the location and acreage are some key factors; the second, the investment for building storage, equipment, devices and many other required matters is usually a quite enormous figure, for example, SF invested over 8 billion yuan to complete the whole chain. Therefore, the financial standing of Deppon concerns a lot with exploiting a new business. But respectively speaking, Deppon can also join hands with other company if there exists too many barriers, whatever for the financial support, the technical or management sharing, this is a good way to set foot in this industry.

\subsection{High Technology and Harsh Policy Requirements}

Currently, the low specialized level of $3^{\text {rd }}$ party logistics has been always perplexing the development of cold chain logistics of China. In the current business of cold chain transportation, most companies mainly put the isolated temperature recorder on the vehicle to separately manage the temperature records. That is a blind spot of management to the cold chain transportation enterprises. Because of the inaccessibility to dynamic condition of transport vehicles for the administrative department or users, including the temperature changing, AC system, driving route, time of unloading and other factors that can't be collected in time, it's impossible to monitor the adjustment to those temporary change effectively. Thus an integrated cold-chain management system for dynamic monitoring and control the distribution temperature is in urgent need. So far, the most widely used technology is RFID, which consists of three parts: Reader, Electronic Tag (transponder), and Application Software System, whose operation principle is that the Reader launches the radio wave power of a specific frequency to motivate the circuit to send out the inner data; then the Reader interprets those data in order, and sending them to the application program to be processed. Such a strict monitoring system indeed needs more shrewd management and shrewd group to operate [2].

On the other hand, the newly revised Food Safety Law of the People's Republic of China, which was passed in April 24th, 2015, and which is called the most strict food safety law in history. In this new version, it is precisely claimed that food carrier or food producer must ensure that the containers, utensils and equipment for storing, transporting, loading and unloading food are safe and innocuous, and kept clean so as to prevent pollution, and must reach the necessary temperature for food safety and meet other special requirements, and that the food may not be transported together with toxic or harmful articles. The new version of food safety law enhances a higher level for food transporter. Except the information processing and transportation, the storage linkage of food is necessary to be paid more attention, including the building of automobile refrigeration house, CA cold stores, multistage temperature refrigerator and many other technologies.

\subsection{Findings}

According to the mentioned above, the feasibility of exploiting cold chain business can be considered from two perspectives: technology and finance. The high and rigorous demand for cold chain products determine the difficult degree of 
building different refrigeration houses, then different cold devices should be used, and as the increasingly strict industry standard and increasingly strict monitoring system of cold chain product, the cost that is applied to purchase devices, to train technician, to build and update the information platform is rapidly increasing, because it is a matter of an opportunity to revolved the whole industry.

And as Chinese government recently intensively released the latest policies, an unprecedented tide of industrial consolidation is coming, a government-oriented reform guides the direction of cold chain participants, which has attracted many other logistics giants to share this market. Anyway, Deppon couldn't miss this opportunity. But facing so many uncertain problems, how to find some solutions to those becomes the next step for the management Deppon.

\section{Suggestions to Deppon}

In fact, regardless of whether considering from the perspective technology or finance, it will be a tough and long road. With the IT revolution fiercely taking place, the traditional logistics network is fading away, what is replacing it is an informational servicing platform under the era of Big Data, where real-time tracking and monitoring makes the food circulation never a simple matter of transporting, and all of the related information, including the time, place, temperature, attribution of goods and condition of goods can be obtained in time. Then according to the development situation of Deppon, some suggestions are brought up to boost the construction of informational platform of cold chain logistics in Deppon.

1. To construct the information platform for the cold chain logistics management

According to the report of FBGS2014, at the era of BIG DATA, the information platform is the foremost task for cold chain logistics. At the same time the rapid development of Deppon, the construction of information platform development must keep pace with the rhythm of enterprise. Since 2010, RF wireless project has been introduced into Deppon, then the following comes the introduction of WINS system combining with the current basis of information experience:

WINS (Wireless Intelligent Net System), which is an intelligent monitoring and management platform, which mainly transmits the information of temperature and humidity to the wireless network (GSM/GPRS).

Communication gateway: Responsible for receiving the wireless communication data of GPRS, temperature and humidity data. And receiving and forwarding instruction from agents, including the vehicle positioning, parameter settings, and so on.

The proxy server: Responsible for analyzing and processing the front-end data. Such as alarm analysis, inventory, control instruction issued by processing.

Database server: storing the dynamic data of business system, etc.

Web server: responsible for achieving the business management functions of $\mathrm{B} / \mathrm{S}$ mode. [8].

Application server: responsible for the operation of the database access control

Network structure is as follows:

Obtaining the data from the temperature and humidity recorder in the front warehouse and the on-board temperature and humidity recorder, the user could take a dynamic observation monitoring. And meanwhile, this system can show the position on e-map according to the longitude and latitude data. Then in the inner system, the data analysis is offered to meet users' need [1].

Based on the current technology tools, including the GPS, RFID, advanced vehicles and so on, Deppon could take these as supplement for the WINS, and its sub-system can also be used to monitor other business. Presently, Yamato has 
established such a system to operate its cold chain business in Shanghai; Rokin logistics is also ready to build an intelligent monitoring net. Therefore, such a system is worth being introduced to Deppon on its cold chain business.

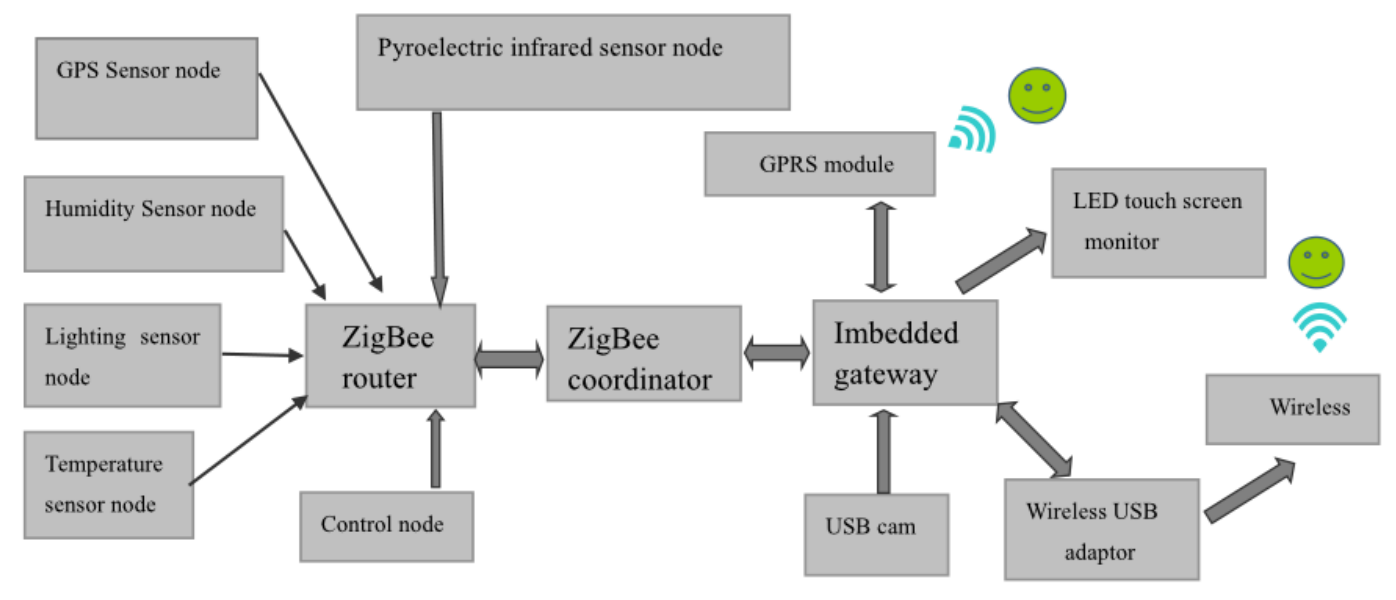

Figure 5. Model of WINS

2. To focus on the government policy tendency to grasp the latest marketing opportunity

The great minds think alike. It's a key time for reforming the cold chain, at the same time, it's also a critical time for the logistics enterprises, to use the latest and most advanced technologies and principle and even those anticipatory. Coupled with the policy guidance, firstly, in 2010, the NDRC issued the Agricultural Cold Chain Logistics Development Planning. The planning put forward that until 2015, our country would establish a number of efficient, large-scaled, modern and crossregional cold chain logistics distribution center. In 2012, the Opinions on supporting the development of agricultural industrialization leading enterprises was released, which pointed that the government support leading enterprises to improve the agricultural product storage, processing, transportation and distribution and cold chain facilities and equipment. In 2013, the State Council adjusted the electricity price for cold storage to the industrial electricity price in Priorities opinions on deepening economic reform of 2013, which greatly eased the current cost pressures of cold chain logistics companies, coupled with the constant local support policies for agricultural cold chain logistics, which greatly enhances the rapid development of cold chain industry. Later in 2014, the State Council issued the ninth national cold chain logistics regulation, which explicitly states that the government must encourage the integration of cold chain infrastructure resources, promote the innovation in logistics technology and application. Compared with the eighth national logistics regulation, this version is more concise and more policy-typed.

Thus, in conclusion, from the Agricultural Cold Chain Logistics Development Planning released in 2010, then the Opinions on supporting the development of agricultural industrialization leading enterprises in 2012, to the Priorities opinions on deepening economic reform of 2013, to the latest ninth national logistics regulation, as it were, it's a comprehensive planning for the development of cold chain logistics, which contains the policy guidance, logistics facilities and equipment, cold chain technologies, cold house building and many other related aspects. What Deppon needs to do first is to make a thorough plan according to its own condition. Another intractable problem may be the talents training, because unlike the ordinary logistics, the cold chain logistics involves in many technological 
process, wherever the product is, there needs some devices to monitor it, then to operate those advanced devices needs a professional technological background. Otherwise the collected data may be inaccurate, which even may affect the company decision-making.

3. To optimize the distribution service and improve the quality and efficiency

During operation, logistics distribution center must strive to satisfy customers' needs. During the distribution activities, to explore the road to reduce costs for customers, to strive to minimize processing costs, and to improve customers' satisfaction, firstly, according to the mentioned above, we have become clear for the barriers that may darken the prospect of Deppon entering the cold chain business: the construction of infrastructure facilities of cold chain, the professional talents for operating the information platform and equipment. System optimization is about how to use reasonable measures or effectively configure various resources, equipment, material, labor, capital, etc., minimizing the cost or resources to achieve the target, or getting the most earnings. In the optimization of distribution network, duo to the necessity of considering the traffic condition, purchasing power, site selection, varieties of products, etc., it's a matter of multi-objective optimization.

Every time document operator confirms an order, he should determine the route through the electronic system, as long as some site where the goods is needed, and in which the number of goods is needed, the model will automatically choose a few routes, so the dispatcher will have some flexible choices according to the real time traffic flow. And according to different goods, including the load of goods, different properties of goods, and the dispatcher can choose different vehicles. Based on different region condition to arrange distribution task, the company ought to avoid a span delivery. (March and Olson, 2011)

Definitely, in the whole process, every batch of goods must have an identity (a number of goods in the company system), thus the goods can be tracked wherever it reaches. Meanwhile, the digital system can be linked with the mobile-phone or email of the consignee.

\section{Conclusion}

In conclusion, as a leading company in TPL industry, it's a strength of Deppon, while as a fresh member in cold chain logistics, there is still a long way ahead. Putting more emphasis on the comprehensive reform of logistics system and improving the customer satisfaction will contribute Deppon to reducing costs in distribution system, and paying more attention to introducing or training professional talents will conduce Deppon to grasp the most advanced management or operating ability. And constantly pushing out some attractive promotion policies according to the obtained Big-data from the customers' feedback and the market information will boost Deppon keep enduring achievement. Coupled with the advanced information platform, the future of Deppon in the cold chain industry will be brighter.

\section{Acknowledgments}

The authors would like to give their thanks to The Education Department of Jilin Province (NO.2015201) and Jilin Social Science Foundation (NO.2014B278) for their financial support. 


\section{References}

[1] W. B. Jia, "RFID Technology in cold chain logistics. Chinese technology information", (A1), (2015), pp. 3-4.

[2] Y. J. Kang, "The management of temperature control based on RFID technology in cold chain logistics", Business modernazition, (2009), pp. 2-4.

[3] C. Kim, K. H. Yang and J. Kim, "Strategy for third-party logistics system: A case analysis using the blue ocean strategy", Omega, vol. 3, (2011), pp. 522-534.

[4] Y.N. Li, D. Cui, W. X. Zhao, J.Y. Li and F.G. Zhao, "A Study on Food Security Problems and Business Credit Crisis in Chinese Food Enterprises", Advance Journal of Food Science and Technology, vol. 7, no. 7, (2015), pp. 501-506.

[5] Y. N. Li, J. Y. Li, Z. Lv, T. Y. Li and Y. L. Tang, "Study of online accounts safety and online payments by smart phones", Journal of Software Engineering, vol. 9, no. 4, (2015), pp. 877-885.

[6] J. G. March and J. P. Olson, "Supply chain management strategy planning and operation", Prentice hall, (2011).

[7] Y. M. Qin, "Report on the development of cold chain logistics in 2014", China fortune press, (2014), pp. 46-167.

[8] Y. Wang, "The supervision system of refrige and smart temperature in cold chain transportion", China Automation, (2013), pp. 17.

[9] Q. G. Wu, "The Current Situation and the Countermeasures of China's Cold Chain Logistics Development", China Business and Market, (2011), pp. 2-3.

[10] X. Q. Zhang, "Research on Food Cold Chain Logistics System Collaboration Based on Rough Set Methodology", Journal of Beijing Jiaotong University (Social sciences edition), (2011), pp. 2.

[11] G. F. Zhu, "Bulletin of International Food and Beverage Summit", 2014 China. China Expo, (2014), pp. 17-21. 